\title{
Análise de discurso em perspectiva: teoria, método e análise
}

\author{
Gesualda dos Santos Rasia \\ Professora da Graduação e da Pós-Graduação da UFPR \\ e-mail: gesa.rasia@gmail.com
}

O livro Análise de discurso em perspectiva: teoria método e análise, organizado por Verli Petri e Cristiane Dias, agrega horizontes novos ao edifício epistemológico da AD que se faz no Brasil. O conjunto de textos que compõem a obra resulta de diálogo encetado entre os laboratórios Corpus-UFSM e LABEURB-Unicamp, cujo coroamento emblemático deu-se no I Seminário Interinstitucional de Análise de Discurso. A conversa entre os dois laboratórios mobilizou o cruzamento de outras vozes, de pesquisadores de diferentes e representativas instituições do país, conferindo valor significativo aos textos publicados pela editora da UFSM.

Vale dizer que o mote do evento, qual seja, uma justa homenagem feita à professora Eni Orlandi, precursora da AD no Brasil, materializa-se em discussões que vão muito além de gestos pró-forma, na medida em que a obra confere visibilidade a noções caras por ela desenvolvidas. Noções estas que ressoam nos conjunto de textos, seja na medida em que sua atualidade é reafirmada, seja quando lhes são acrescentados saberes e reflexões. E não poderia ser diferente, em se tratando de disciplina que tem como uma de suas marcas o vir-a-ser, o interrogar-se e reformular-se contínuo.

É o caso da parte de entrada, intitulada "Ciência política e Tecnologia", na qual o texto da homenageada pauta o par paráfrase/polissemia, apontando para o recobrimento, para os silenciamentos que há no aparente efeito de polissemia no enunciado "País rico é país sem pobreza". A inesgotável problematização desse par confirma a sempre necessidade de idas e vindas no caminho nem sempre simétrico que vai da teoria à análise e vice-versa. Essa não simetria é foco também do texto "O funcionamento do movimento pendular próprio às análises discursivas na construção do 'dispositivo experimental' da análise de discurso", de Verli Petri, em que a autora explora múltiplos sentidos da figura do pêndulo, no afã de pautar os sentidos da $\mathrm{AD}$ como disciplina de entremeio teoria-análise, sempre exposta à imprevisibilidade. Tal metáfora, tão apropriada, reporta ao vai e vem incessante entre discursos, o próprio do trabalho 
do analista. Compõe ainda a primeira parte, o texto de Cristiane Dias, no qual a noção de silêncio, trabalhada por Orlandi (1992), é revisitada sob as injunções de uma outra ordem: a da tecnologia. Ordem esta cujos sentidos produzidos são de completude, onipotência, onipresença, universalidade e unidade. E a relação sujeito-linguagem necessariamente é afetada, atravessada nessa passagem do silêncio à verbalização, de forma lapidar, no texto "Linguagem e tecnologia: uma relação de sentidos".

A segunda parte, "A urbanidade em diferentes materialidades discursivas", foca discursividades relativas ao corpo social, em sua dimensão política, humana e estética. José Horta Nunes ocupa-se, no texto "Marchas Urbanas", em pautar a tensão entre o jurídico e o político nos enunciados que circularam nas redes sociais relativos às marchas emergentes no ano de 2011. Interessante notar que embora o foco seja outro e específico, a conversa entre as partes da obra se mantém produtiva, visto que a dimensão tecnológica atravessa o estudo de Horta Nunes, focando o trajeto da escrita digital à escrita do acontecimento, com suas peculiaridades, convergências e singularidades.

Além desse exemplo de liame tecido entre as diferentes partes da obra, outro aspecto que ratifica sua qualidade é a presença de noções teóricas que não se limitam à retomada, mas que emergem na perspectiva da problematização e do acréscimo. É o caso da noção de montagem discursiva, discutida por Rejane Arce Vargas, também na segunda parte, no texto "Discurso em circulação e acontecimento: descrever montagens". Em um gesto de denúncia, a autora mostra como se dá o recobrimento do político na substituição aparentemente inocente do par comunidade/favela, em discursos sobre a criminalidade em mídias online. Ainda nessa parte, marca presença forte "O corpo enquanto objeto discursivo", de Maria Cristina Leandro Ferreira, que tece percurso com passagem por múltiplos territórios, tais como "a arte, chegando à religião, envolvendo a antropologia, cruzando a medicina" e ainda "olhando mais de perto o campo da psicanálise e o da análise do discurso, em sua relação de afetação constitutiva com o corpo." A dimensão política e humana do espaço urbano é abordada por Marcos Barbai, em análise de manifestações políticas e culturais da Avenida Paulista como espaço de litígio e simulacro, no texto "Sujeito e espaço: na Paulista, 'tá dando pra se viver"? Barbai puxa os fios da linguagem como "lugar importante de apontamentos: aquilo que não vai bem quando vivemos juntos". Mas o faz tomado pelo simbólico que produz os múltiplos sentidos na Paulista. E também de poesia é feito o espaço urbano, por isso dela pode ocupar-se o olhar discursivo sobre a rua, que se faz presente no texto de Eliana de Almeida, intitulado "Rimas e telas: a rua no (dis)curso", em que se faz presente um contraste da linguagem da poesia com a 
do videoclipe, tornando evidente como os sentidos do urbano podem ir da construção lírica à denúncia e a silenciamentos, via jogos de linguagem e de sonoridade.

"A produção de sentidos no ensino" é o título e o foco da terceira parte da obra, fortemente relacionada à primeira parte, na medida em que circunda a relação linguagem-sujeitotecnologia, tocando em questão nodal do século XXI. Claudia Castellanos Pfeiffer parte do campo da herança retórica, com o intuito de problematizar que sentidos a escolarização constrói hoje quando ensina a escrever textos, priorizando a arte do bem redigir em detrimento do opinar, no texto "Língua e sujeito na escola". O estatuto da retórica e da argumentação, tratados por Pfeiffer, constituem porta de entrada para a discussão que Sérgio Augusto Freire de Souza faz, no questionamento de seu texto "Para quem é o discurso pedagógico?", dado seu anacronismo em relação à emergência do sujeito da era tecnologizada, constituído por novas formas de saber. Sérgio revisita as tipologias de discurso elaboradas por Eni Orlandi nos anos 90 e afirma a necessidade da passagem do discurso com funcionamento autoritário para o discurso polêmico. Também desse tema ocupa-se Débora Massmann, que se propõe a pensar como a escola do século XXI é afetada pelas novas tecnologias, como estas modificam a produção e a circulação do conhecimento na sociedade. E, sobretudo, os efeitos de sentido dessa modificação nas relações do sujeito com o saber no sistema de ensino brasileiro. Diante disso, a pertinência do título que nomeia seu texto: “Ontem, hoje e amanhã: ainda a questão do ensino".

A quarta parte do livro, intitulada "O Sujeito no e do discurso", dialoga com campos diversos do conhecimento para pautar a noção de sujeito. Exemplo disso é o texto de Pedro de Souza, que submete elementos da fonologia a uma abordagem discursiva, pautando a voz como lugar de subjetivação, concebendo-a como lugar de enunciação exposto à interpretação, porque submerso em uma ordem discursiva e não ausente de resistência. "O sujeito no discurso: modulações operadas pelo drama na voz" é o título do texto. Fugindo de fórmulas desgastadas e investindo em densidade, Lauro Baldini rediscute o estatuto da psicanálise para pautar a noção de sujeito na teoria pêcheutiana do discurso. Seu estudo, nomeado "Sujeito e subjetividade: psicanálise e análise do discurso" coloca noções como "determinação" e "interpelação" diante da presença-ausência da noção de gozo na obra de Pêcheux e instiga a pensar a partir mesmo dessa contradição. Para refletir acerca da resistência que se manifesta no sujeito que não é só do discurso, mas também no discurso, Belmira Magalhães põe em cena diferentes linguagens/materialidades, dentre elas manchetes de revistas, outdoors e propagandas, a partir das quais tematiza a relação ideologia/inconsciente, no estudo "Sujeito no e do discurso: 
pensando a resistência". E o faz analisando centralmente a expressão "você pode", reiteradamente repetível aos olhos do sujeito contemporâneo sob diferentes inscrições, em que pese a contradição de suas impossibilidades sociais e econômicas. A partir disso a autora discute como se dá a exaltação da construção do sujeito livre, completo, supostamente capaz de realizar o que quiser. Outro campo de conhecimento com o qual a AD dialoga é o da literatura, no texto de Maurício Beck: "O processo da interpelação ideológica em Kafka: da ignorância culposa ao humor rebelde", no qual o autor se pergunta, ao final, "se o efeito de desmontagem e desmistificação do eu pelo viés do humor não é correlato à crítica teórica que a Análise do Discurso e a psicanálise fazem ao sujeito-ego-pleno e a uma suposta interpelação ideológica todo poderosa sem fissuras e contradições?" Fechando a quarta parte, o texto de Maria da Conceição Fonseca-Silva, "Língua, memória discursiva e efeitos de sentido", trata da relação memória e acontecimento a partir do fato histórico da eleição da militante Dilma Rousseff à presidência do Brasil, na medida em que este fato articula as noções de língua e de memória discursiva para pensar o efeito metafórico na constituição de lugares de interpretação.

Como fecho do livro, a V parte, nomeada "A formação da nação e as diferentes formas de institucionalização do saber”, principia com texto de Amanda Scherer, no qual há uma ampla retomada da obra de Eni Orlandi e dos sentidos teórico-metodológicos de seu legado, ainda produtivo. Esse traçado é peculiar porque dá visibilidade à contribuição ímpar dessa pesquisadora para a constituição e consolidação da AD brasileira. Além disso, o tom da escrita, com traços de subjetivação acerca do modo como Amanda Scherer constituiu sua história pessoal de analista de discurso, é modelar do alcance de Orlandi, no ensaio-memória emblematicamente intitulado "A casa miticamente comum”. Ana Zandwais, no mesmo bloco, responde à questão “Como caracterizar uma nação: entre os domínios históricos e discursivos”, de resposta aparentemente simples, a partir de algumas variáveis complexificadoras como, por exemplo, a unidade histórica de uma nação, que é apenas imaginariamente construída. Ainda, o fato de que há processos históricos de dominação, conjunto de fatores que levam a autora a se perguntar e responder sobre o que dizer da língua enquanto caracterizadora de uma nação. Mônica Zoppi-Fontana, nessa parte, discute os sentidos da oficialização da língua portuguesa, no texto "Equívocos da/na língua oficial", refletindo acerca de alguns aspectos constitutivos de seu estatuto político-jurídico e de seu funcionamento enquanto domínio de memória. A autora mostra como no percurso histórico dessa constituição foi tecido um corpo imaginário que condensou metonimicamente a própria denominação "Língua Portuguesa”. É também sobre os sentidos da institucionalização do português como língua nacional que versa Mariza 
Vieira da Silva, no estudo intitulado "Língua nacional-escola nacional", a partir do contexto da colonização e da escravização e como a nomeação da língua deslizou, em documentos históricos, para "comum”. Para além da nomeação, a autora analisa como se dá a produção de sentidos, especialmente no que tange à distribuição do saber escolarizado em relação com a língua nacional.

Em suma, as cinco partes que compõem as 310 páginas da obra constituem-se, cada uma delas, micro-universos nos quais a Análise do Discurso é densamente discutida/trabalhada. E o fazem de modo que esses micro-universos entabulem conversa com o todo, de um lado, porque pautam noções recorrentes, tais como silêncio, memória, paráfrase, polissemia, língua, sujeito, sentido, nação... De outro lado, porque tais noções quer sejam pensadas na perspectiva de velhos ou novos objetos de discurso, não deixam de trazer ao centro das discussões os deslocamentos epistemológicos que têm marcado esses 30 anos da AD brasileira. Três décadas não ausentes de "coragem teórica", valendo-me aqui de palavras que Lauro Baldini tributou em seu texto a Michel Pêcheux. Coragem esta que nos impulsiona sempre, a nós, analistas de discurso, a "Casa miticamente comum", que nos legou Eni Orlandi e que está tão bem erigida em Análise de Discurso em Perspectiva. 